sometimes necessary to be a little thick skinned, not to say ruthless, to protect the interest of disabled people in wheelchairs. I wondered how parents of such children coped. On the other hand many of the places we visited welcomed us warmly, even admitting us free or at a reduced rate. A lady who ran an orchid farm opened on her day off to receive us.

All the children enjoyed the beach, including Christopher, who sunbathed in a deckchair supervising the building of sandcastles, with his portable ventilator on the sand beside him. Two of the girls went into the sea. Hauling wheelchairs to the edge of the sea across soft sand was hard work. An easier method with Victoria was to give her a piggy back ride to the sea. Once she was in the water it was quite easy to keep her afloat thanks to a foam lifejacket invented at Chailey.

\section{No bar to disco dancing}

The grand finale was the Saturday night cabaret at our hotel. The show was garish, deafening, and brightly lit. Our four young charges were agog. Vicki, who often has her head on her chest, partly through depression and partly because of the effort required to hold it up, sat for three hours with her head bolt upright, eyes shining with fascination. The disc jockey was quite drunk and frequently muddled up his patter and equipment. He took it in good part when Victoria fended him off with a gentle kick of her one good leg to his groin when he became a little familiar with one of our nurses. Two children, with a little help, picked a raffle ticket; the hotel manager won both prizes and donated them to Victoria and Chris. The evening ended with wheelchair disco dancing. The other hotel guests were a rather listless bunch and there had been no dancing until Bill, our leader, organised the waitresses to link hands with our children and ourselves. The floor shook to the stomping of feet and the rumbling of wheelchairs. This rather shamed the other guests into taking to the floor. Wheelchairs glided, couples smooched, the disc jockey was drowned by the pounding beat, and soon it was 1 am and time for bed. We had taken a few risks; few ventilated patients get held aloft in a nurse's arms to join in a circle of dancers. Also Vicki had a fit from excitement later that night. But there had been no mistaking the excitement and smiles on all their faces. We had also livened up the hotel for an evening. The manager gamely said he would have us back another year. Next morning we left early and the staff got up an hour earlier to give us breakfast and see us off.

It had been an exhausting week. It had also been expensive. Are such trips worth while? The local estate agents, who footed the $£ 2500$ bill for the accommodation, seemed to think so. Indeed Chailey benefactors often prefer their money to go on specific projects like this rather than to be sunk into some general fund. The nurses tell me that the long term performance and mood of disabled children often improve after such trips. I am in no doubt as to the short term benefits; it was clear from the children's faces that they were having a good time.

Disability arouses powerful feelings, not always positive. We had received a few hostile glares, but also much kindness and support from the public. My own feelings towards the disabled have changed. I lived for a week with four severely disabled young people and got to know and like them. I now find I look at disabled people as individuals with human worth rather than as objects of pity, or worse. I recommend such a trip to any doctor working with the disabled.

\title{
Dry haricot bean: A new continence aid for elderly men?
}

\author{
Anup Patel
}

An 82 year old man had been registered blind owing to bilateral myopic macular degeneration. Since starting treatment with oral diuretics from his family practitioner he had been troubled by urinary incontinence. He had previously had no lower urinary tract symptoms. In August 1989 he was visited by a childhood friend who had lived and worked as an itinerant labourer on sheep farms in the Australian outback. His friend had experienced similar urinary problems during the latter part of his career as a sheepherder and seemed able to maintain urinary continence by inserting a dry haricot bean into the external urethral meatus. He removed and replaced the bean with specially adapted blunt ended tweezers every 24-48 hours.

The patient, impressed by his friend's tale, decided

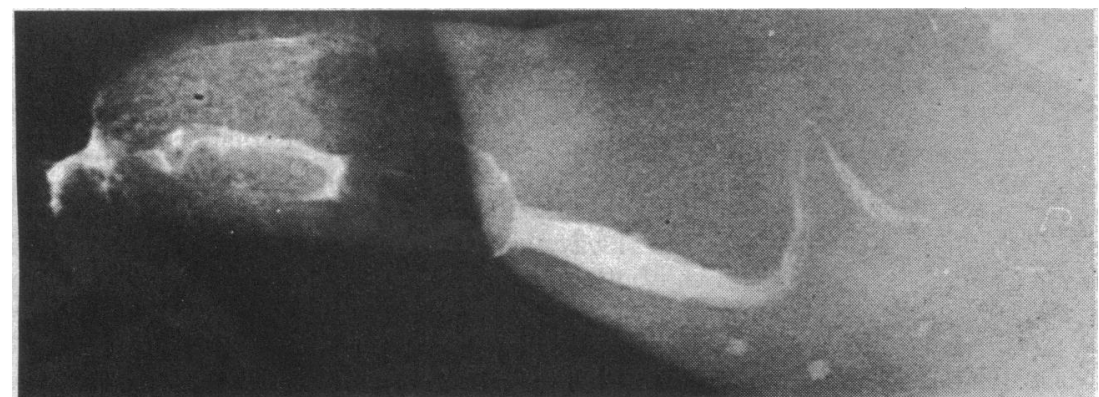

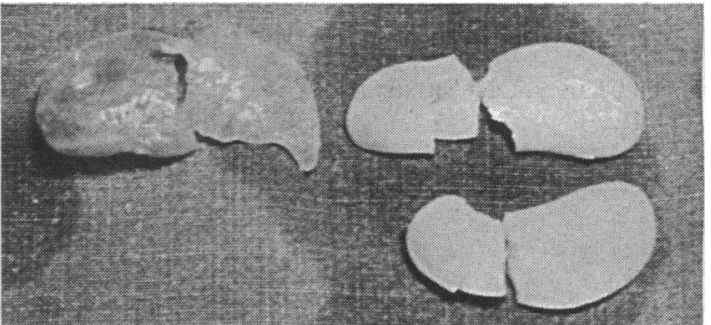

FIG 2-Where has it bean?

to try the technique. Before his friend returned to Australia the patient took a dry haricot bean from his ample supply. Two days later he tried to retrieve the bean from the external urethral meatus with a pair of angled hair plucking tweezers. Because of his poor sight the retrieval process proved to be too difficult. After several minutes it was apparent that rather than removing the bean he had pushed it further into the urethra. Embarrassed at his predicament, he did not seek help until three days later, when his penis had become swollen and painful and micturition was "difficult." He was immediately referred to hospital as an "unusual case of urinary retention."

The patient was in severe discomfort from an oedematous penis, which was maximally indurated in the region of the midpenile urethra. The bladder was impalpable. An ascending urethrogram (fig 1) confirmed the presence of a filling defect in the penile 
urethra. At panendoscopy the haricot bean, which had begun to sprout, was removed in three parts (fig 2) with a combination of long artery forceps and cystoscopic biopsy forceps. The patient was catheterised and given a course of broad spectrum antibiotics until the penile oedema and induration had resolved. His diuretic treatment was stopped.

At follow up two months later he was asymptomatic and no longer suffered from urinary incontinence. Uroflowmetry showed no evidence of a urethral stricture, and he was discharged.

\section{Discussion}

Urinary incontinence, especially as a sequel to treatment with diuretics, remains a troublesome symptom in elderly men and often causes both dismay and embarrassment. When surgical or drug treatment is not appropriate a variety of continence aids, ranging from the penile clamp to the condom catheter, can be used. None of these devices are, however, free of complications.

Maintaining continence with a dry haricot bean placed just within the external urethral meatus is a novel and ingenious concept based on the ball valve stopcock principle, and this case shows that it is effective. But this new continence aid is not without potential hazard, especially in the unwary elderly patient with compromised vision or poor manual dexterity. Although psychosexual disorders in young men are often associated with introducing a foreign body into the urethra or bladder, 'there is no evidence to support this premise in elderly men.

Bichler KH. Foreign body injuries of urethra and bladder in the young: their psychosexual background. Urol Int 1971;26:161-70.

\section{Natural history of the disappearance of various products in the course of the transfer from socialist economy to regulated market}

\section{G E Falkowski}

This study was undertaken to assess certain common features in the disappearance of various products and goods from the general commodity circulation (GCC). This particular period (summer and autumn 1990), 45 years after the end of the second world war, is called by the government "the period of transfer to regulated market economy."

\section{Material and methods}

The study is based on observations of the situation in Moscow (population over 7 million) during eight consecutive months of 1990 (January to August). The methods used included the five known human senses: sight, hearing, smell, taste, and touch. The sixth sense,

\section{"I am happy to have lived my life in order to prove someone else's theory" - $\mathrm{M}$ ZHVANETSKY.}

also known as common sense, was applied in various situations that intermittently appeared in the course of observation. In some instances the seventh sense, so called intuition, also had to be used, but it rarely helped. All the animals observed did not receive human care whereas the human subjects were treated according to principles of laboratory animal care formulated by the National Society for Medical Research and the guide to the care and use of laboratory animals prepared by the National Academy of Sciences and published by the National Institutes of Health (NIH publication No 80-23, revised 1978).

Student's $t$ test for paired values, the non-parametric Mann-Whitney test, univariate regression analysis with the two tailed Fisher's exact test, and $\chi^{2}$ analysis were all used in order to obtain maximum objectivity.

Bakulev Institute of Cardiovascular Surgery, Moscow

G E Falkowski, MD, professor of paediatric cardiovascular surgery

BrMed J 1990;301:1433-4
III); partial absence of item (stage IV); total absence (stage $\mathrm{V}$ ).

\section{STAGE I: RUMOURS}

This stage starts with a colleague or neighbour mentioning casually that a certain item is absent in the GCC. The phase might begin with the words "they say" or "I was told" (difference between words: statistically negligible). The statement can concern either the direct absence of the item or the possibility of a twofold or threefold increase in its price, in which case it begins with the same words but more commonly includes the phrases "I have heard" or "Did you watch TV last night?" The crucial question that may arise during this phase, "Who are 'they'?" can never be answered and certainly should be investigated further.

The most characteristic feature during this particular period of observation is that no matter how illogical and absurd the stage I might have seemed it invariably led to stage II. The time difference between the stages depended mostly on the susceptibility of the subjects and lasted from a few hours to several days, depending on the product or item in question. The difference was not statistically significant $(\mathrm{p}>0 \cdot 2)$.

\section{STAGE II: QUEUES}

This feature, which is also known in international literature as "lines," has always been extremely characteristic of Russian society. In previous years queues were mostly sporadic, chaotic, inexplicable, or seasonal. They also occurred in other countries, even in the so called developed countries. As an example of a non-parametric queue we joined in a line in New York City as a matter of habit. Using this habitual approach, based on a decades old principle that includes getting into the line first and finding out what the people are standing for afterwards, we learned that this line led to an art gallery featuring an exhibition of Picasso's works; hence it was distinguishable from the queues of stage II as being mostly of a spiritual nature.

The Russian queues we studied were without exception material $(\mathrm{p}<0.00001)$. They could be observed at $6 \mathrm{am}$ outside a shop that opens at $9 \mathrm{am}$, at which point they resembled a many tailed monster. Some lines were almost invisible, but at the entrance to the shop several serious looking individuals with lists in their hands could be seen. This meant that this particular line was 